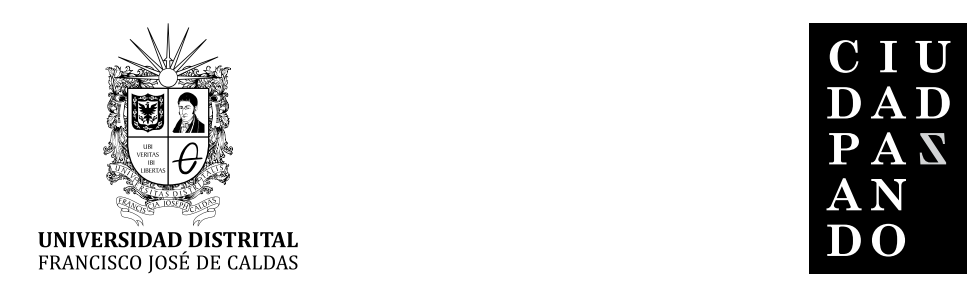

DOSSIER

Artículo de investigación científica

\title{
El papel de la memoria colectiva: una experiencia con mujeres víctimas del conflicto en el municipio de Granada, Cundinamarca ${ }^{1}$
}

The role of collective memory: an experience with women victims of the conflict in the municipality of Granada, Cundinamarca

O papel da memoria colectiva: uma experiência com mulheres vítimas do conflito no município de Granada, Cundinamarca

\section{Giovanny Eduardo Bogoya Caviedes ${ }^{2}$}

Para citar este artículo: Bogoya, G. (2017). El papel de la memoria colectiva: una experiencia con mujeres víctimas del conflicto en el municipio de Granada, Cundinamarca. Revista Ciudad Paz-ando, 10(2), 29-39.

doi: https://doi.org/10.14483/2422278X.12220

Fecha de recepción: 17 de junio de 2017

Fecha de aprobación: 26 de enero de 2018

\footnotetext{
1 Este artículo es derivado del trabajo de grado titulado "Derecho a la verdad y a la reconstrucción de la memoria colectiva de las mujeres víctimas del conflicto, en la vereda San Raimundo del municipio de Granada, Cundinamarca”, investigación desarrollada en 2015 y presentada para optar al título de especialista en Derechos Humanos. Un agradecimiento a Ligia María Aldana Hernández, enlace de víctimas del conflicto en el municipio de Granada.

2 Magíster en Educación, Universidad Pedagógica Nacional. Docente vinculado a la Secretaría de Educación del Distrito. Correo electrónico: eduardo.bogoya@gmail.com
} 


\section{RESUMEN}

A raíz del escalonamiento del conflicto que vivió el sur del departamento del Tolima hacia la última década del siglo XX, muchas mujeres desplazadas iniciaron un proceso de duelo en búsqueda de la reivindicación de sus derechos. El trabajo desarrollado durante el 2015 en el municipio de Granada, Cundinamarca, representó una apuesta teórico-metodológica por determinar: ¿de qué manera las experiencias de las mujeres promueven la difusión de la memoria colectiva y la reconstrucción de su tejido social? Para ello, se realizó una investigación etnográfica de tipo descriptiva, que arrojó como principal hallazgo la necesidad de sistematizar los testimonios de las víctimas, lo anterior como medio para conservar su memoria colectiva.

Palabras clave: conflicto armado, derechos humanos, desplazamiento forzado, memoria colectiva, mujer.

\section{ABSTRACT}

Since the escalation of the conflict in the south of the Tolima department in the last decade of the XX century, many displaced women began a process of mourning in search of the claim of their rights. The work developed in the year 2015 in the Granada - Cundinamarca municipality, represented a theoretical and methodological commitment, to determine how do women's experiences promote the diffusion of collective memory and the rebuilding of their social fabric? For this purpose, a descriptive ethnographic research was carried out, which showed as the main finding the need to systematize the testimonies of the victims as the means to preserve their collective memory.

Keywords: armed conflict, collective memory, forced displacement, human rights, woman.
Após a estagnação do conflito que ocorreu no sul do departamento do Tolima na última década do século XX, muitas mulheres deslocadas iniciaram um processo de luto em busca da reivindicação de seus direitos. O trabalho desenvolvido em 2015 no município de Granada - Cundinamarca, representou uma aposta teórico-metodológica para determinar: ¿de que forma as experiências das mulheres promovem a difusão da memória coletiva e a reconstrução de seu tecido social? Para isso, foi realizada uma investigação etnográfica de tipo descritivo, que revelou como principal achado: a necessidade de sistematizar os testemunhos das vítimas, como meio de preservar sua memória coletiva.

Palavras-chave: conflito armado, deslocamento forçado, direitos humanos, memória coletiva, mulher. 


\section{Introducción}

Este documento surge de una investigación realizada durante el 2015 con mujeres víctimas del conflicto armado, residentes en el municipio de Granada, Cundinamarca; la cual fue motivada como una respuesta frente al desconocimiento sobre la violación de derechos humanos de la que fueron víctimas familias desplazadas del sur del Tolima, que se asentaron en la vereda San Raimundo entre 2005 y $2011 .^{3}$

El municipio de Granada, ubicado en la provincia de Sumapaz sobre las estribaciones de la cordillera oriental, desde la primera década del presente siglo, ha sido un constante receptor de familias desplazadas por la violencia que provienen del departamento del Tolima, población que fue desarraigada por el contexto hostil y de conflicto que sufrieron tres municipios del sur de este departamento - Ataco, Planadas y Rioblanco- durante 2002-2010.

Sobre este contexto surgió la siguiente pregunta problema: ¿de qué manera las historias de vida de las mujeres en situación de desplazamiento en la vereda San Raimundo de Granada, Cundinamarca, facilitan la difusión de su memoria colectiva y la reconstrucción de su tejido social? Se buscó, dando respuesta a la pregunta anterior, resolver el objetivo general de caracterizar la manera en que las vivencias de las mujeres víctimas del conflicto contribuyen al fortalecimiento de la memoria colectiva de la población desplazada y a la re-construcción de su tejido social; lo anterior sumado a los objetivos específicos de identificar, conocer y describir las necesidades, experiencias y roles sociales que tienen lugar en el entramado mujer-desarraigo. Para establecer un acercamiento vivencial a la problemática aquí planteada, se diseñó una metodología de investigación cualitativa con un alcance descriptivo basado en el método etnográfico, apoyado en las siguientes técnicas: observación participante, entrevista y grupos de discusión.

La estructura del documento se divide en cinco apartados: primero, en el marco de los derechos positivos de la mujer durante el siglo XX, se realiza una breve contextualización de la jurisprudencia internacional; segundo, desde la lectura de los derechos humanos aparece el concepto de desplazamiento forzado como una categoría de análisis del problema investigativo; tercero, a partir del relato se presenta la memoria colectiva como una desafío grupal por reconstruir tejido social; cuarto, tiene lugar la apuesta metodológica llevada a cabo con la comunidad;

3 Según cifras de la Red Nacional de Información (RNI, 2017), entre marzo de 2005 y diciembre de 2011 se asentaron en el municipio de Granada 208 personas desplazadas, correspondiente al $2.63 \%$ de las 7927 que llegaron a la provincia del Sumapaz en el mismo periodo. Granada se constituye en el sexto municipio de la provincia con mayor presencia de desplazados, los otros son: Fusagasugá (5338), Silvania (827), Cabrera (352), Arbeláez (312), Venecia (287), Tibacuy (192), Pandi (172), Pasca (127) y San Bernardo (112) por último, se presentan los hallazgos y recomendaciones que suscitaron de la investigación.

\section{Jurisprudencia internacional sobre los derechos de las mujeres: un breve repaso desde el siglo $\mathrm{XX}$}

A partir de la primera mitad del siglo XX, el reconocimiento de los derechos de las mujeres ha sido normativizado a través de la jurisprudencia internacional. En 1928 se establece el primer órgano intergubernamental creado para la protección de los derechos de las mujeres: Comisión Interamericana de Mujeres (CIM), cuyo objetivo principal es formular políticas contra la violencia a la mujer y en pro de la igualdad de género en América (OEA, 2016).

Otros cuerpos políticos de relevancia internacional que han apostatado por los derechos de esta población, son: Comisión de la Condición Jurídica y Social de la Mujer (CSW) de 1946, como un organismo derivado de la Organización de las Naciones Unidas (ONU) que vela por la igualdad de género y empoderamiento de la mujer (ONU, 2017); Convención Interamericana para Prevenir, Sancionar y Erradicar la Violencia contra la Mujer "Convención de Belém do Pará" de 1994, la cual ofrece mecanismos de protección contra la violencia a la mujer (OEA, 1995); Convención sobre la Eliminación de Todas las Formas de Discriminación contra la Mujer (CEDAW) de 1979, cuya finalidad es erradicar efectivamente cualquier forma de discriminación contra la mujer, apoyada en la Declaración sobre la eliminación de la discriminación contra la mujer de 1967 (ACNUR, 2001); Declaración sobre la eliminación de la violencia contra la mujer de 1993, que insta a la necesidad de una aplicación universal a los derechos de las mujeres (ONU, 2008); Protocolo Facultativo de la Convención sobre la eliminación de todas las formas de discriminación contra la mujer (OP-CEDAW) de 1999, que reconoce la competencia de la CEDAW para recibir comunicaciones que aleguen violación a los derechos de las mujeres y cuya población forme parte de un Estado miembro (ONU, 2010).

Además se habla de igualdad de derechos entre mujeres y hombres, en pactos o tratados como: la Declaración Universal de los Derechos Humanos (DUDH) de 1948, preámbulo y artículo 16 (ONU, 2015); Pacto Internacional de Derechos Económicos, Sociales y Culturales (PIDESC) de 1966, artículos 3 y 7 (CNDH, 2012); Pacto Internacional de Derechos Civiles y Políticos (ICCPR) 1966, artículos 3, 6 y 23 (COPREDEH, 2011); Convención Americana de Derechos Humanos "Pacto de San José" de 1969, artículos 4, 6 y 17 (OEA, 2014).

Colombia no podría estar ajena a estos procesos, en 1954 bajo el gobierno de Gustavo Rojas Pinilla (19531957), se promulga el Acto Legislativo Número 3 de 1954 sobre la ciudadanía de las mujeres y el derecho político a sufragar en las elecciones, facultad que sería ejercida hasta 1957 (SUIN, 2017a). Por medio del Decreto 1972 de 
1933, las mujeres pueden acceder a la educación superior (MEN, 2017); la Ley 28 de 1932 permite a la mujer casada la libre administración de sus bienes (ICBF, 2016a); el Decreto 2820 de 1974 otorgó la patria potestad tanto al hombre como a la mujer (CSJ, 2015); el Decreto Ley 999 de 1988 suprimió la obligación a la mujer casada de llevar el apellido de su esposo (ICBF, 2016b); la Ley 83 de 1931 permitió a las mujeres trabajadoras recibir directamente su salario (SUIN, 2017b); en el Decreto 2531 de 1965 y en la Ley 50 de 1990 se dictan normas sobre sus condiciones laborales (Alcaldía Mayor de Bogotá, 1990); por último, el artículo 43 de la Constitución, defiende la igualdad de derechos y oportunidades entre hombres y mujeres, asimismo, alega que la mujer no puede ser sometida a ningún tipo de discriminación (CPC, 1991). La Corte Constitucional (2000), en la Sentencia C-371 expresa la situación histórica de la mujer en Colombia, así:

No hay duda alguna de que la mujer ha padecido históricamente una situación de desventaja que se ha extendido a todos los ámbitos de la sociedad y especialmente a la familia, a la educación y al trabajo. Aun cuando hoy, por los menos formalmente, se reconoce igualdad entre hombres y mujeres, no se puede desconocer que para ello las mujeres han tenido que recorrer un largo camino. Baste recordar que bien entrado el siglo veinte, las mujeres en Colombia tenían restringida su ciudadanía, se les equiparaba a los menores y dementes en la administración de sus bienes, no podían ejercer la patria potestad, se les obligaba a adoptar el apellido del marido, agregándole al suyo la partícula "de" como símbolo de pertenencia, entre otras limitaciones. (p. 56) En efecto, el proceso de reivindicación de los derechos de las mujeres, en el ámbito regional, nacional o global, ha sido un arduo trabajo histórico dirigido por su misma población, quienes al pasar de los años han ganado más espacios en diferentes esferas de la sociedad. En el contexto colombiano, los mayores avances se ubican después de la asamblea constituyente de 1991, cuando los derechos de las mujeres obtuvieron relevancia constitucional. En relación con el caso de las mujeres de Granada, ellas también han sufrido la negación de sus derechos e integridad, situación que ha conllevado a su organización en pro de su memoria colectiva y de hacer frente a la vulnerabilidad de su contexto, dinámicas que solo han sido posibles a través del liderazgo y trabajo comunitario.

Es por ello que en el campo teórico se hizo uso de unas categorías de análisis desde donde se apoyó el proceso de intervención en la comunidad - desplazamiento forzado y memoria colectiva-, las cuales se presentan en los siguientes apartados, ofreciendo una proximidad entre estas y los derechos humanos.

\section{Desarraigo, el caso de las mujeres de Granada}

En el marco del conflicto, un gran número de personas fueron desplazadas por el ambiente hostil característico en el sur de Tolima ${ }^{4}$, muchas de estas mujeres fueron separadas de su familia y afectadas en su dignidad, después de ser desarraigadas de sus condiciones de vida. Con esto se consuma una clara violación de los derechos humanos, según García (2002): "Los derechos humanos se consagran - se reconocen, se atribuyen, se tutelan: como se prefiera- en tanto el sujeto es persona, ser humano, mujer, varón, sin otro título que lo abarque o lo mejore, que lo exalte o lo distinga” (p. 31). A esta población se le desconoció su condición de seres humanos, las mujeres fueron víctimas de dicha vulneración al no reconocer su dignidad como personas.

La trascendencia de los derechos humanos no permite discusión, por el contario, se convierten en el andamiaje que sostiene toda sociedad; siendo más ambicioso, puede decirse que es la estructura fundamental de cualquier Estado, tomando a Carbonell (2001): "En los Estados democráticos, los derechos se han convertido en una escala de evaluación de la legitimidad de los poderes públicos" (p. 325). Entonces ¿por qué en los Estados democráticos se vulneran los derechos humanos? ¿Lo anterior, sería una ambigüedad del lenguaje jurídico?

En el contexto de conflicto que se vive en Colombia, los derechos humanos y el Derecho Internacional Humanitario (DIH), representan un complemento encaminado a la protección de la condición humana. El objetivo fundamental de los derechos humanos es reafirmar la dignidad de las personas en sus relaciones y frente al Estado, garantizando cualidades constitutivas en todos los seres humanos sin diferencia alguna. Por su parte, el DIH tiene como objetivo proteger a la población que es o ha sido víctima de conflictos armados (Benavides, 2003). Aunque la población estudiada para esta investigación fue víctima en el marco del conflicto armado vivido en su región de origen, la apuesta teórico-metodológica apuntó hacia la visibilidad de las experiencias de las mujeres como una

\footnotetext{
4 De acuerdo con el informe "Dinámicas del conflicto armado en Tolima y su impacto humanitario" de la Fundación Ideas para la Paz (2013), el conflicto se ha centrado en el suroccidente del departamento, en especial, en la zona del cañón de Las Hermosas - antiguo baluarte y escondite de las FARC—, que desde el 2010 sufrió las arremetidas de la Fuerza Aérea y el Ejército, en cabeza de la Fuerza de Tarea del Sur del Tolima. En la zona hacían presencia las FARC: Frente 21, Columna Móvil Miller Salcedo, Columna Móvil Alirio Torres y Columna Móvil Héroes de Marquetalia; Paramilitares: Bloque Tolima (AUC; 1999-2005), Autodefensas Campesinas del Magdalena Medio Antioqueño (ACMM; 1997-2006), y últimamente bandas criminales. Según la misma entidad, entre 2000 y 2012 se reportaron 201479 desplazados, de los cuales el $60 \%$ eran de la región suroccidental: Ataco $21 \%$, Rioblanco 14\%, Chaparral 8\%, Planadas 5\%, Rovira 5\%, Coyaima 4\% y San Antonio 3\% (FIP, 2013).
} 
expresión de inconformismo frente al resquebrajamiento de su condición humana, es decir, se realizó una lectura desde la perspectiva de los derechos humanos más allá del conflicto.

Sobre este panorama, tiene lugar el desplazamiento forzado como uno de los crímenes de lesa humanidad tipificado por el Estatuto de Roma, artículo 7 "Deportación o traslado forzoso de población” (OEA, 2000), crimen del cual fue víctima la población proveniente del sur del Tolima. Para esta investigación no se asumió a las mujeres solamente como víctimas del conflicto armado, por el contario, se entendieron como víctimas generales en el marco de una serie de violaciones constantes a sus derechos humanos. Para exponer esto, vale la pena traer considerar a Aponte (2005):

Pero el hecho real es que en Colombia se trata de un escenario extremadamente confuso en el cual no es de ninguna manera fácil distinguir acciones en conflicto armado y acciones por fuera de él. Por ejemplo, si se produce el desplazamiento de un grupo de personas que habitan un territorio en el cual es lucrativa la siembra de productos ilegales, y quienes lo hacen son actores a su vez involucrados en escenarios de conflicto armado, o de disputas territoriales, en estricto sentido no se trata de una infracción al derecho humanitario; pero se trata, en todo caso, de un desplazamiento forzado, que es un crimen internacional y que hace parte de lo que se puede denominar el "núcleo duro de derechos humanos. (p. 109) Desde esta perspectiva, las mujeres requieren protección de sus derechos, no solo como víctimas del conflicto, sino también como víctimas en general. Con base en ello, hablar de desplazamiento implica complejizar un fenómeno que perjudica o pone en peligro varias cualidades propias del ser social, al decir de Bello (2000) sobre cómo el perjuicio a las mujeres extralimitó sus condiciones materiales:

Los aspectos psicosociales y culturales del desplazamiento son el eje sobre el cual se hace posible cualquier intento de remediar daños, de reconstruir identidades y tejido social, de dignificar a la población, en su mayoría errante y anónima, que ha sufrido el despojo de sus tierras, de sus pertenencias y de la esencia de su ser social. (p.17) Surge la necesidad de atender esos aspectos psicosociales y culturales presentes en su dignidad, visibles desde un enfoque de género, según Álvarez (2014):

Los estudios de género buscan analizar cómo se configura el fenómeno mujer o el fenómeno hombre, en qué dinámicas, en qué tipo de relaciones, en qué procesos educativos y formación de hábitos se va naturalizando un modo particular de ser humano llamado mujer u hombre. (p. 70) Dinámicas, relaciones, procesos y hábitos que se han fragmentado debido a la falta de integración de su cultura tradicional campesina, la cual se ve inmersa en un nuevo territorio receptor donde reinan otras prácticas culturales que al unísono configuran el sujeto llamado mujer.

En los estudios sociales, la dimensión del género da valor y reivindica cualquier opción de vida, buscando garantizar su trasegar en la sociedad. Para el caso de las mujeres víctimas del conflicto, su alternativa de vida en el desarraigo debe propender hacia la defensa de sus saberes colectivos, los cuales están enmarcados en su identidad de género. Para Lamas (2007) el género es una construcción cultural que posibilita la interpretación del mundo desde diversos roles sociales, que generalmente se limitan por una suerte de prohibiciones simbólicas, siendo este el caso de las mujeres desplazadas del Tolima, quienes personifican los roles de madre, campesina, trabajadora y líder comunitaria, que en comunidad construyen memoria.

En resumen, en la población desplazada tuvo lugar una suerte de secuelas que no se limitaron a su condición de desarraigo, es decir, a raíz del desplazamiento aparecieron otras consecuencias - psicosociales y culturales- que se hicieron necesarias indagar. Desde esta mirada, la comunidad reclama el reconocimiento de su memoria colectiva como un derecho taxativo de su condición humana, la cual se encuentra ligada a una perspectiva de género que representa un constructo sociocultural permeado por tradiciones, roles, expresiones, territorios, dinámicas, cosmovisiones, entre otras, que las define como mujer sujeto de derechos, con tradiciones culturales e históricas.

\section{Memoria colectiva: una apuesta por construir desde los recuerdos}

En el ámbito de los derechos humanos, la memoria aparece como una necesidad de la población víctima por conservar su historia viva, reproducir sus vivencias, compartir sus experiencias y sus recuerdos individuales, hasta alcanzar un macro recuerdo colectivo; este proceso solo es posible en el marco de una comunidad que las identifi$\mathrm{ca}$, de un entramado social en constante cambio, pero que en conjunto constituyen memoria colectiva.

En el concepto desarrollado desde la primera mitad del siglo XX, se establece una diferencia entre este y la memoria histórica; así, la segunda se podría definir como los acontecimientos que recrean la historia nacional, pero la memoria colectiva es más compleja de precisar, debido a que se restringe a un grupo más limitado con características particulares que se afianzan en el tiempo y en el espacio. Las historias de vida de la población desplazada responden a una memoria minimizada que se fortalece con el transcurrir del tiempo y la variación del territorio, memoria que adquiere relevancia en la comunidad que interactúa cotidianamente con sus recuerdos. Para Halbwachs (2004), la memoria colectiva difiere de la histórica en dos aspectos: 
Es una corriente de pensamiento continuo, de una continuidad que no tiene nada de artificial, ya que del pasado sólo retiene lo que aún queda vivo de él o es capaz de vivir en la conciencia del grupo que la mantiene. Por definición, no va más allá de los límites de este grupo. [...] De hecho, es difícil decir en qué momento ha desaparecido un recuerdo colectivo, y si ha salido del todo de la conciencia del grupo, porque precisamente basta con que se conserve en una parte limitada del cuerpo social para que podamos volver a encontrarlo en cualquier momento. Existen, en efecto, varias memorias colectivas. Es el segundo rasgo por el que se diferencian de la historia. (p. 84) Corriente que en el contexto del desarraigo obtiene protagonismo, se expresa en un ejercicio por dominar recuerdos colectivos que aún están presentes en el grupo social, el cual, mediante procesos complejos de pensamiento, concreta relaciones y experiencias que configuran la memoria de las comunidades desplazadas. Existe en las mujeres, por ejemplo, tradiciones, roles, configuraciones, representaciones e imaginarios que han sido transmitidos por medio de la oralidad y que se conservan en los integrantes del grupo, quienes a pesar de su fragmentación conservan ciertas tradiciones que los fortalece como colectividad.

Siguiendo con Halbwachs (2004), la memoria de una sociedad recompone su pasado hasta donde alcanzan los recuerdos de los grupos por los que está compuesta. En medio del conflicto, se combinan una serie de subjetividades que formen parte íntegra del grupo, y que en el ejercicio social determinan procesos de memoria colectiva. Es así, como en el exilio las comunidades se organizan en un nuevo territorio, el cual configura un escenario donde convergen diversos recuerdos que generan identidad al compartir ciertas cualidades humanas que los reconoce como grupo social.

Desde esta mirada se debe indicar lo expuesto por Betancourt (2004): "La memoria está, pues, íntimamente ligada al tiempo, pero concebido este no como el medio homogéneo y uniforme donde se desarrollan todos los fenómenos humanos, sino que incluye los espacios de la experiencia" (p. 126). Entonces, la voz de las mujeres representa las subjetividades que son posibles a través de la experiencia, la cual está vigente en la memoria de la población, sin importar la linealidad del tiempo y el desarraigo al cual han sido forzadas.

La memoria colectiva no se anquilosa en un solo espacio temporal y geográfico, por el contrario, se desenvuelve en escenarios alternos donde convive el grupo social sobre el territorio, en donde se generan lazos que construyen experiencias a partir de los recuerdos, sin importar que este sea su lugar de origen o de confinamiento; así, al decir de Mendoza (2005):

Al igual que el tiempo, el espacio contiene acontecimientos y construye recuerdos, puesto que es en los lu- gares donde las experiencias se guardan, sea en los rincones, en los parques, en los cafés o en cualquier otro sitio donde los grupos viven su realidad y allí dan significado a sus experiencias. (p. 6) Por consiguiente, en la situación de desarraigo perduran los recuerdos de la población desplazada, memorias que generan significado en la identidad de roles sociales en medio de un entramado cultural permeado por el pasado, pero que cobra validez en el presente, en este caso desde la territorialidad de Granada donde las mujeres viven su realidad.

Los recuerdos generan memoria y esta adquiere una notable importancia en la vida social de las personas, se expresa en un proceso continuo de vivencias e intercambio de experiencias que afianzan el trasegar de un grupo social, en este caso, de las poblaciones campesinas provenientes del sur del Tolima, quienes ahora comparten una nueva geografía sin dejar de lado su historicidad. Este hecho se vale de lo trazado por Larraín (2001), quien presenta a los humanos como seres históricos, dado que viven en una dimensión temporal, y como seres territoriales, puesto que organizan su vida en espacios físicos donde reproducen sus expresiones. Como resultado de esta articulación, las personas producen vivencias y reproducen recuerdos que contribuyen a la configuración de la memoria colectiva de la población.

Definir la memoria colectiva implica el reconocimiento de las experiencias de los sujetos, sin menoscabar el poderío de sus recuerdos en la construcción de estas. Se establece un desafío grupal donde convergen aspectos, tanto del pasado como del presente, que conjugados construyen colectividad; así, la memoria colectiva "es esa construcción de voluntades humanas que trata de construir un sentido del presente a través de las palabras y las imágenes, y que se permite dibujar el pasado desde la necesidad de la comprensión del presente" (González y Reyes, 2012, p. 88), es un escenario crítico donde los integrantes de una comunidad modifican su presente a través del correlato de las experiencias del pasado.

La memoria colectiva es un escenario estratégico para la articulación entre pasado y presente; así, según Bellelli (1999), se estructura en una aproximación sistemática al pasado, la cual asume tanto dinámicas sociales generales como procesos personales. Aunque en medio del conflicto las víctimas sufren afectaciones diferenciales de acuerdo con su condición social, son las mujeres quienes soportan una mayor fractura en su tejido social debido a que encarnan la base emocional de sostenimiento y manutención del hogar, aun así, es esta misma población la encargada de reivindicar sus derechos, y entre estos, la memoria colectiva como la esencia fundamental que las identifica y diferencia dentro de su comunidad. Las experiencias del pasado ahora circulan en los saberes del presente, "El término memoria colectiva, por su parte, aspira a dar cuenta de las formas de conciencia del pasado compartidas por 
un grupo social en el presente" (Aravena, 2003, p. 92). En síntesis, la memoria colectiva es un reconstrucción de la identidad social, desde la unión de subjetividades que se trenzan en el ejercicio de lo cotidiano, de aquellas mujeres que en la lejanía de sus tierras reclaman por medio de sus historias de vida la dignificación de su ser.

En consecuencia, en el marco de los derechos humanos tiene lugar una conexión entre desplazamiento forzado y memoria colectiva, entendiendo esta última como un proceso complejo de organización del presente con sentido en el pasado que requiere la participación de la comunidad desplazada para no distanciarse de sus tradiciones; por ello, el entender las condiciones en las cuales se trenza esta conexión, motivó una apuesta vivencial que tuvo como protagonistas a mujeres víctimas del conflicto.

\section{Mujeres víctimas del conflicto en la vereda San Raimundo}

Nos amenazaron, yo senti mucho miedo y vendi los animales a como me los quisieran pagar, le eché candado a la casa y con el dolor más grande dejé la finca y me despedi de mis vecinos, que al igual que yo también se fueron de la vereda

Mujer desplazada de Ataco, Tolima

La metodología utilizada en la investigación fue cualitativa con un enfoque descriptivo basado en el método etnográfico, se asumió esta metodología con el propósito de determinar la manera en que las vivencias de las mujeres promueven la difusión de su memoria colectiva y la reconstrucción de su tejido social; además, con la etnografía se logró obtener datos cualitativos relacionados con la realidad que vivieron y viven las mujeres, el enfoque permitió también la lectura de las prácticas de las mujeres dentro de su contexto:

El enfoque etnográfico se apoya en la convicción de que las tradiciones, roles, valores y normas del ambiente en que se vive se van internalizando poco a poco y generan regularidades que pueden explicar la conducta individual y de grupo en forma adecuada. (Pérez, 1994, p. 284) A través de esta metodología se alcanzó un acercamiento a sus historias de vida: "La investigación etnográfica se propone descubrir las estructuras y sistemas dinámicos característicos de los hechos observados en los procesos humanos y sociales. El método que se aplica en estos estudios corresponde a la realidad observada" (Chica, 2004, p. 23). Aquí el reto fue entender cómo después de ser desarraigadas de sus raíces, lo vivido influye en sus dinámicas de socialización del presente, en este caso, en el municipio de Granada.

Utilizar lo cualitativo cobró toda fuerza para el propósito de la investigación, debido a que buscó describir el contexto observable en la cotidianidad de las mujeres, aquello que se hizo visible a través de sus expresiones, relatos, narrativas y que respondió necesariamente a sus historias de vida. Así lo describe Castillo (2005):

La investigación cualitativa implica la utilización y recogida de una gran variedad de materiales - entrevista, experiencia personal, historias de vida, observaciones, textos históricos, imágenes, sonidos- que describen la rutina y las situaciones problemáticas y los significados en la vida de las personas. (p. 51) Por lo anterior, se aplicó la investigación cualitativa haciendo uso de las siguientes técnicas para su abordaje: observación participante (matriz de observación), grupos de discusión (matriz textual) y entrevista abierta (formato de transcripción).

El escenario que sirvió como referente empírico fue el "hogar grupal" de la vereda San Raimundo, al cual se accedió con el apoyo de las profesionales de la "Casa de la mujer" del municipio de Granada, en especial, con las trabajadoras sociales del programa de enlace de víctimas para el conflicto. Para llegar al lugar de encuentro era necesario ingresar por la cabecera municipal, y desde allí abordar un transporte vehicular particular hasta el centro de la vereda. Durante las sesiones de campo no se presentaron inconvenientes, el trabajo se ejecutó según lo planeado. La implementación de las técnicas se describe a continuación.

\section{Observación}

Se desarrolló en el 2015 (de febrero a noviembre, entre las 2 y las 6 p.m., de cada viernes) dentro del "hogar grupal" de la vereda San Raimundo del municipio de Granada, ubicado en el salón comunal de San Raimundo, el cual se encuentra administrado por la alcaldía de Granada y cuyos alrededores son en su mayoría rurales. Las participantes eran mujeres madres cabeza de familia, víctimas del conflicto, mayores de edad, aproximadamente asistían entre 25 y 30 mujeres a cada sesión, dentro de la asistencia también se encontraban las trabajadoras sociales del proyecto, las cuales cumplían el rol de apoyo y orientación en el grupo. La estrategia fue observar a las mujeres cuando compartían en grupo: talleres, actividades, granjas integrales, ferias empresariales, deportes, almuerzos colectivos, la evidencia se escribió en la matriz de observación. Con esta técnica se buscó identificar las necesidades, representaciones y transformaciones de los roles de las mujeres como víctimas del conflicto; luego de su implementación se planteó la siguiente síntesis:

- Las mujeres hacen uso de sus historias de vida para compartir en grupo, demuestran una actitud alegre, con confianza y familiaridad.

- El "hogar grupal" sirve de encuentro en sus tiempos libres, el espacio es utilizado para afianzar sus lazos de 
amistad o empatía, se le da prevalencia a actividades espontáneas de socialización y al trabajo en equipo. Mientras unos grupos cocinaban, otros jugaban parqués, tejían a mano, practicaban aeróbicos, hacían danza dirigida o simplemente descansaban. Los grupos se alternaban las actividades cada viernes.

- Las mujeres desarrollan su creatividad por medio de la realización de talleres teórico-prácticos (agricultura, emprendimiento, cocina, costura, fomi, muñecos, alfabetización), los cuales eran dirigidos por mujeres líderes de la misma comunidad y se realizaban conjuntamente después de compartir la comida. La actitud de las participantes era animada y con disposición para realizar los talleres. Para su realización, se llevaba control de asistencia, participación y cumplimiento, el cual era evaluado asignando tareas y compromisos para la casa.

- Las mujeres se empoderan de saberes prácticos que les ayudan a afianzar su autonomía laboral, lo que se evidenció por medio de la realización de las tareas y la propuesta de nuevas temáticas o estrategias para mejorar su productividad en el mundo laboral.

\section{Grupos de discusión}

Se citaron cuatro grupos de diez mujeres cada uno, con los cuales se realizó una entrevista grupal durante $60 \mathrm{mi}-$ nutos y un segundo encuentro donde se socializaron las respuestas dadas a las preguntas orientadoras. Los criterios de selección fueron: mujeres entre 30 y 50 años, madres cabezas de hogar a cargo de hijos menores de edad, desplazadas por el conflicto vivido en el sur del Tolima. Con la técnica se buscaron variantes de respuesta a los tres objetivos específicos de la investigación (identificar, conocer y describir). Su ejecución arrojó los siguientes resultados:

- Expresan con dolor los recuerdos que les dejó el conflicto.

- Se asumen como población víctima en situación de desplazamiento.

- Consideran al municipio de Granada y la vereda San Raimundo como un escenario en conjunto que les brinda una nueva oportunidad para recuperar parte de sus tradiciones.

- Declaran que en la provincia de Sumapaz se viven dinámicas propias de la guerra.

- Se reconocen como el bastión económico y emocional de la familia.

- Alegan la poca ayuda del Estado ante el fenómeno del desplazamiento.

- Entienden que, para alcanzar mejores condiciones de vida para ellas y sus familias, deben ser laboralmente autosuficientes.

\section{Entrevista}

Se utilizó la entrevista como una técnica que contribuyó a escuchar el testimonio desde el relato de sus historias de vida. Se tomó como muestra poblacional a diez mujeres, desplazadas y habitantes de San Raimundo. La técnica se desarrolló en tres fases que tuvieron como antesala la elaboración de las preguntas: primero la selección de las participantes; segundo el encuentro; tercero la transcripción y análisis de lo conversado. De los resultados de la entrevista se pudo concluir que:

- Las mujeres transitan con dolor su duelo, en sus discursos se evidencia impotencia, rabia, frustración e incluso culpabilidad por lo sucedido.

- Sienten un vacío tras la pérdida de sus esposos y demás familiares.

- Han sentido rechazo e indiferencia por gran parte de la sociedad.

- No están satisfechas económica y socialmente con las labores ahora realizadas.

- Prefieren trabajar en labores propias del campo, así sean mal remuneradas.

- Expresan el deseo de conocer la verdad sobre lo sucedido con algunos seres queridos.

- La mayoría tienen el anhelo de volver a sus tierras.

- Exigen justicia penal para los responsables de su desplazamiento.

- Consideran fundamental que los otros conozcan su historia para que los hechos no se repitan.

Con base en los relatos y experiencias extraídos en la implementación de las tres técnicas, se encontraron una serie de coincidencias presentes en los resultados, entre estas, los hechos de violencia más recurrentes de los que fueron víctimas las mujeres son: amenazas, muertes de seres queridos, desplazamiento, despojo de bienes y pertenencias, reclutamiento forzado y desapariciones. Por otro lado se encuentra la importancia de las historias de vida como parte fundamental en la constitución de identidad de las mujeres, las protagonistas delegan culpabilidad por acción u omisión de agentes del Estado, los recuerdos como una realidad del pasado que se niegan a olvidar, el territorio de Granada y San Raimundo se constituyen en escenarios de afianzamiento de saberes en colectivo, la población espera la finalización del conflicto para con ello volver a sus tierras, las mujeres se empoderan en su rol social de trabajadoras, agentes de productividad e independencia económica, la familia se constituye como el baluarte fundamental de su existencia y el tránsito de la memoria en la consolidación de colectividades.

Estas simultaneidades implican que existió uniformidad en los resultados arrojados por las tres técnicas, en las cuales hubo un marcado interés por socializar sus experiencias en pro de la reconstrucción de su memoria colectiva, lo anterior desde el empoderamiento de roles 
que las fortalecen como grupo social, político y productivo; además, determina que los relatos se encuentran permeados por los recuerdos y experiencias que aún tienen validez en la subjetividad de las mujeres.

\section{Hallazgos y recomendaciones}

Como vestigio de esta investigación, se puede concluir que el testimonio de las mujeres responde a las violaciones de derechos humanos de que fueron víctimas, pero estos relatos contribuyen en dinámicas colectivas que las fortalecen en su tejido social. En efecto, las protagonistas expresan por medio de sus historias de vida, los anhelos por superar el duelo de sus pérdidas, tanto espirituales como físicos, propósito que se forja en comunidad con otras mujeres que han sufrido en igual medida las huellas de la guerra. Estos deseos, aunque tienen su génesis en el conflicto vivido en el sur del Tolima, se consolidan en la territorialidad de Granada, en especial, en la vereda San Raimundo.

La otredad desempeña un papel fundamental en la construcción de identidades. Si bien las mujeres no se separan de su subjetividad por el solo hecho de cambiar de un espacio geográfico a otro, sí se generan dinámicas alternas de empoderamiento donde los otros cobran relevancia al ser reconocidos como diferentes por su riqueza social y cultural, que les permite crecer a todos en comunidad. En específico, de los habitantes originarios del municipio, de la población que no es desplazada de la región o de aquellos que nunca se han topado de cerca con los avatares de la guerra, pero que al unísono construyen comunidad.

Desde su propia narración, el testimonio de las mujeres permitió conocer una parte de la verdad de los hechos, enunciar y hacer visible el daño que ocasionó el conflicto en su dignidad; asimismo, la violación de los derechos humanos implica la inoperancia del Estado Social de Derecho, visión que es expresada por las propias mujeres. En relación con la reconstrucción de su tejido social, no obstante, el desarraigo generó una ruptura en su comunidad, también se demostró un deseo por hacer colectividad en otro contexto y con los suyos, fue aquí donde adquirieron relevancia aspectos como los recuerdos, las identidades y las experiencias en la construcción de nuevas dinámicas de convivencia.

La memoria colectiva encontró en los recuerdos un mecanismo de difusión, situación que se pudo vislumbrar en las narrativas que hacen sobre su pasado, el cual es compartido a pesar de que genera sentimientos encontrados en gran parte de las protagonistas. Igualmente, las experiencias compartidas en el "hogar grupal" demuestran el deseo por no perder su memoria, al contrario, existe un esfuerzo por transmitir esos saberes a los más jóvenes, por ejemplo, el trabajo en el campo. Al mismo tiempo, las identidades configuran un rescate de la memoria colectiva, las mayores no quieren que se pierdan las costumbres que las identifica dentro de una gran familia, razón por la cual afianzan su identidad defendiendo vínculos comunes en el grupo, por ejemplo, cocinar y compartir los alimentos.

$\mathrm{Al}$ analizar la experiencia, es posible entender que la necesidad más imperante de estas mujeres es establecerse laboralmente para generar mejores ingresos que contribuyan al bienestar propio y de sus familias, estabilidad laboral que representa la cultura del agro presente aún en las actividades diarias que realizan, las cuales no se separan de esa tradición intrínseca que las define como campesinas. De esta manera, los roles sociales que identifican a las mujeres son: madre, cabeza de hogar, sostén económico de la familia, trabajadora, emprendedora, campesina, estudiante, líder socio comunitaria.

En cuanto a las afectaciones propias que sufrieron las mujeres, estas fueron vulneradas en su tejido social debido al quebrantamiento de sus derechos. Como consecuencia de los hechos derivados del conflicto, se generó fragmentación de las familias, pérdidas económicas, sufrimiento emocional, ruptura de su cultura, cambios en la ejecución de roles, desarraigo y la obligación de someterse a otras prácticas en un contexto extraño, aunado a la carencia de políticas públicas que respondan a las necesidades planteadas por las mujeres. De igual modo, se halló que las mujeres carecen de un acompañamiento jurídico y psicosocial que les permita hacer visible su testimonio y la vulneración de sus derechos, dentro del municipio no se identificaron escenarios institucionalizados que promuevan la difusión de la memoria colectiva. Con el afán de contrarrestar la fragilidad de la memoria, surge la necesidad de sistematizar los relatos de las víctimas, puesto que sus experiencias son la única garantía de la perdurabilidad de su historia.

Por lo anterior, las apuestas políticas, investigativas, académicas e incluso pedagógicas, podrían indagar sobre líneas de investigación que exploren el fenómeno del desplazamiento en el municipio de Granada. Pueden aparecer líneas como: enfoque de género, derechos de las mujeres, dinámicas socioculturales en el desarraigo, memoria colectiva e identidad, pedagogía de los derechos humanos, territorio, desplazamiento y escuela, empoderamiento de las mujeres, entre otras, que examinen sobre la relación que se teje entre derechos humanos y mujeres desde la espacialidad de Granada.

Al mismo tiempo, aparecieron unos interrogantes que giran en torno la importancia de generar espacios comunitarios para las mujeres y promover acciones tendientes a la recopilación de sus experiencias, tanto desde la institucionalidad del Estado como fuera de este: ¿qué tipo de alcances tiene el testimonio de las mujeres en la conexión violencia de género-derecho a la verdad?, ¿cómo podría la articulación entre mujer-empoderamiento originar estrategias de autosuficiencia económica en la población desplazada?, ¿en qué sentido las historias de vida de las 
mujeres pueden dinamizar prácticas demandantes de la memoria histórica?, ¿de qué forma las políticas públicas reproducen imaginarios colectivos que legitiman la reducción del derecho a la verdad de la población violentada?, ¿desde qué enfoque productivo se puede establecer un trabajo comunitario que centre su análisis en las necesidades de las mujeres desarraigadas? Son interrogantes que germinaron de la investigación y que pueden ser debatidos en posteriores trabajos.

Por consiguiente, en la población víctima existe la necesidad de que las mujeres logren empoderarse sociopolíticamente para re-construir su tejido social y difundir su memoria colectiva, para así garantizar acceso a la justicia y a las medidas de reparación; lo anterior, apoyado en una intervención certera del Estado que debe hacer mayor presencia en el territorio y apostar por un efectivo acompañamiento a esta comunidad. Se alegan mayores mecanismos gubernamentales que faciliten la participación de las víctimas, en correspondencia con el título IX de la Ley 1448 de 2011, en especial, el primer capítulo "De la participación efectiva y los espacios de participación de las víctimas" (Ministerio del Interior, 2012), haciendo énfasis en el artículo 264 sobre las mesas de participación, en este caso, desde el municipio de Granada.

Se planteó acercar este trabajo a la institucionalidad del municipio, debido a que proyecta una serie de incertidumbres sobre las relaciones que trenzan las mujeres en comunidad desde sus voces, testimonios e historias de vida en medio del conflicto. Por lo anterior, se propuso el desarrollo de un proyecto edu-comunitario sobre los derechos humanos con mujeres de la vereda San Raimundo, el cual busca la articulación — una vez se consolide- entre la "Casa de la mujer y centro integral para restablecer los derechos" de la Alcaldía de Granada, con "el hogar grupal" de la vereda San Raimundo.

\section{Referencias}

Alcaldía Mayor de Bogotá (21 de abril de 1990). Ley 50 de 1990. Recuperado de http://www.alcaldiabogota.gov.co/sisjur/normas/ Norma1.jsp?i=281

Alto Comisionado de las Naciones Unidas para los Refugiados (ACNUR). (2001). Convención sobre la Eliminación de Todas las Formas de Discriminación contra la Mujer. Recuperado de http://www.acnur. org/fileadmin/scripts/doc.php?file=fileadmin/Documentos / BDL/2001/0031 (2017, 20 de abril).

Álvarez, A. (2014). Los discursos otros, criticas al universalismo occidental. Bogotá D.C.: Ediciones Desde Abajo.

Aponte, A. (2005). Estatuto de Roma y procesos de paz: reflexiones alrededor del "proyecto de alternatividad penal" en el caso colombiano. En Woischnik, J. (Ed.). Temas actuales del derecho penal internacional. (pp.83-116). Berlín: Konrad-Adenauer-Stiftung E.V.

Aravena, A. (2003). El rol de la memoria colectiva y dela memoria individual en la conversión identitaria mapuche. Estudios Atacameños, 26, 89-96. https://doi.org/10.4067/S0718-10432003002600010
Bellelli, G. (1999). Emoción y memoria colectiva. El recuerdo de acontecimientos públicos. Psicología politica. 18, 101-124.

Bello, M. (2000). Impactos psicosociales del desplazamiento y estrategias de intervención. En M. Bello, E. Martín y F. Arias (Eds.), Efectos psicosociales y culturales del desplazamiento. (pp.15-27). Bogotá: Universidad Nacional de Colombia.

Benavides, J. (2003). Nociones de derechos humanos y de derecho internacional humanitario. Medellín: Señal Editora.

Betancourt, D. (2004). Memoria individual, memoria colectiva y memoria histórica: lo secreto y lo escondido en la narración y el recuerdo. En A. Torres, A. Jiménez (Eds.), La práctica investigativa en ciencias sociales. (pp.123-134). Bogotá: Universidad Pedagógica Nacional.

Carbonell, M. (2001). Los derechos en la era de la globalización. Ciudad de México: Porrúa.

Castillo, M. (2005). Aprendiendo con el corazón. El tejido andino en la educación quechua. La Paz: Plural Editores.

Chica, F. (2004). Etnografía e investigación comunitaria. Bogotá D.C.: Universidad Santo Tomás.

Comisión Nacional de los Derechos Humanos (CNDH). (2012). Pacto Internacional de Derechos Económicos, Sociales y Culturales, y su Protocolo Facultativo. Ciudad de México: CNDH.

Comisión Presidencial Coordinadora de la Política del Ejecutivo en materia de Derechos Humanos (COPREDEH). (2011). Pacto Internacional de Derechos Civiles y Politicos. Recuperado de http://www. aprodeh.org.pe/documentos/marco-normativo/legal/Pacto-Internacional-de-Derechos-Civiles-y-Politicos.pdf Constitución Política de Colombia (CPC). (1991). Artículo 43.

Corte Constitucional. (2000). Sentencia C-371/00. Recuperado de http://www.corteconstitucional.gov.co/RELATORIA/2000/C-371-00.htm

Corte Suprema de Justicia (CSJ). (2015). Decreto 2820 de 1974. Recuperado de http://www.cortesuprema.gov.co/corte/wp-content/ uploads/subpage/mujer/mujer/Leyes\%20Mujer\%20PDF/DECRETO\%202820\%20DE\%201974.pdf

Fundación ideas para la Paz (FIP). (2013). Dinámicas del conflicto armado en Tolima y su impacto humanitario. Recuperado de http:// archive.ideaspaz.org/images/DocumentoMonitoreo_ConflictoArmado_Tolima_Julio2013.pdf

García, S. (2002). Los derechos humanos y la jurisdicción interamericana. Ciudad de México: Universidad Nacional Autónoma de México.

González, M. y Reyes, I. (2012). Acontecimientos y personajes de México en la memoria colectiva de los ciudadanos. Revista Internacional de Ciencias Sociales y Humanidades, 12(1), 83-109.

Halbwachs, M. (2004). La memoria colectiva. Zaragoza: Prensas Universitarias de Zaragoza.

Instituto Colombiano de Bienestar Familiar (2016a) (ICBF). Ley 28 de 1932. Recuperado de http://www.icbf.gov.co/cargues/avance/docs/ley_0028_1932.htm

Instituto Colombiano de Bienestar Familiar (2016b) (ICBF). Ley 999 de 1988. Recuperado de: http://www.icbf.gov.co/cargues/avance/docs/decreto_0999_1988.htm (2017, 21 de abril). 
Lamas, M. (2007). El género es cultura. En Bragança de Miranda. (Ed). V Campus Euroamericano de Cooperación Cultural. Madrid: Organización de Estados Iberoamericanos para la Educación, la Ciencia y la Cultura - OEI.

Larraín, J. (2001). Identidad Chilena. Santiago de Chile: LOM Ediciones.

Mendoza, J. (2005). Exordio a la memoria colectiva y el olvido social. Athenea Digital, 8, 1-26. https://doi.org/10.5565/rev/athenead/ v1n8.217

Ministerio del Interior (2012). Ley de víctimas y restitución de tierras $y$ decretos reglamentarios. Bogotá D.C.: Imprenta Nacional de Colombia.

Ministerio de Educación Nacional (MEN). (2017). Decreto 1972 de 1933. Recuperado de: http://www.mineducacion.gov.co/1621/ articles-102983_archivo_pdf.pdf (2017, 21 de abril).

Organización de los Estados Americanos (OEA). (1995). Convención Interamericana para Prevenir, Sancionary Erradicar la Violencia contra la Mujer (Convención de Belém do Pará). Recuperado de https:// www.oas.org/dil/esp/convencion_belem_do_para.pdf (2017, 20 de abril).

Organización de los Estados Americanos (OEA). (2000). Estatuto de Roma de la Corte Penal Internacional. Recuperado de https:// www.oas.org/36ag/espanol/doc_referencia/Estatuto_Roma. pdf (2017, 25 de abril).

Organización de los Estados Americanos (OEA). (2014). Convención Americana de Derechos Humanos (Pacto de San José). Recuperado de https://www.oas.org/dil/esp/tratados_B-32_Convencion_ Americana_sobre_Derechos_Humanos.pdf (2017, 20 de abril).

Organización de los Estados Americanos (OEA). (2016). Estatuto de la Comisión Interamericana de Mujeres. Recuperado de http://
www.oas.org/es/CIM/docs/CIMStatute-2016-ES.pdf (2017, 20 de abril).

Organización de las Naciones Unidas (ONU). (2009). La eliminación de la violencia contra la mujer. Resolución 7/24. Recuperado de http://ap.ohchr.org/Documents/S/HRC/resolutions/A_HRC RES_7_24.pdf (2017, 20 de abril).

Organización de las Naciones Unidas (ONU). (2010). Protocolo Facultativo de la Convención sobre la eliminación de todas las formas de discriminación contra la mujer. Recuperado de https://www.unicef. org/panama/spanish/MujeresCo_web.pdf

Organización de las Naciones Unidas (ONU). (2015). Declaración Universal de los Derechos Humanos. Recuperado de http://www. un.org/es/documents/udhr/UDHR_booklet_SP_web.pdf (2017, 20 de abril).

Organización de las Naciones Unidas (ONU). (2017). Comisión de la condición jurídica y social de la mujer. Recuperado de: http://undocs.org/es/E/CN.6/2017/2 (2017, 20 de abril).

Pérez, G. (1994). Técnicas de investigación en educación social. En J. Sáez (Ed.). El Educador Social. (pp.277-304). Murcia: Universidad de Murcia.

Red Nacional de Información (RNI). (2017). Unidad para las víctimas. Recuperado de http://cifras.unidadvictimas.gov.co/Home/Desplazamiento

Sistema Único de Información Normativa-Juriscol (SUIN). (2017a). Acto Legislativo Número 3 de 1954. Recuperado de http://www. suin-juriscol.gov.co/viewDocument.asp?id=1825652

Sistema Único de Información Normativa-Juriscol (SUIN). (2017b). Ley 83 de 1931. Recuperado de http://www.suin-juriscol.gov.co/ viewDocument.asp?id=1627577 